\title{
Salt Rejection by Sea Ice during Growth ${ }^{1}$
}

\author{
R. A. Lake and E. L. Lewis \\ Department of Energy, Mines and Resources, Atlantic Oceanographic Laboratory \\ Bedford Institute, Dartmouth, Nova Scotia
}

It is demonstrated that rejection of salt at a freezing ice-water interface takes place at least in part by cyclic convective processes occurring within the small interstitial spaces located in the first few centimeters of ice above the interface. This invalidates the assumption of the diffusive boundary layer utilized by previous authors and shows that nearinterface temperatures are subject to cyclic variations. This result should be generally true for phase changes in aqueous solutions with floating ice, and it must be considered as a modification to current theories of solidification. It is shown that large vertical tubular structures attended by smaller tributary tubes exist within the growing sea ice sheet; this arrangement almost certainly indicates horizontal migration of brine toward preferred drainage areas in a manner analogous to the catchment area of a river and its tributaries.

\section{INTRODUCTION}

The low salinity of sea ice as compared with the sea water from which it is formed is well known. It is of fundamental importance both in regard to the properties of sea ice and to the circulation in the underlying waters. Measurements taken by Weeks and Lee [1962] as well as data of previous experimenters indicate that salt is rejected during the freezing process both immediately at the interface and subsequently by drainage from the existing ice sheet as further accretion occurs.

The rejection of brine at the interface may be considered as a special case of the general problem of solute distribution between the solid and the liquid phases. This problem has received much attention in the metallurgical literature, and successive attempts have been made to account qualitatively for the solidliquid interface topography, dendritic growth, etc., in terms of the concept of constitutional supercooling, originally described by Tiller et al. [1953]. Constitutional supercooling theories as applied to aqueous solutions describe an enhanced solute concentration in the liquid layer immediately adjacent to the freezing interface and postulate diffusion as the mechanism by which the solute is transported away from

${ }^{1}$ Contribution 131 of the Bedford Institute.

Copyright (C) 1970 by the American Geophysical Union. the interface. It was realized that this simplification was unsuited to many practical circumstances, owing to the onset of convection induced by either thermal or solute gradients. Experimental results illustrating the temperature fluctuations in metallic alloy ingots grown horizontally have been given by Cole and Winegard [1964]. A theoretical study of the effects of convection has been given by Burton et al. [1953], Burton and Slichter [1958], and Wagner [1954], wherein it was assumed that the diffusion process was confined to a thin boundary layer in the immediate vicinity of the interface and that convective processes provided the means of solute transport at greater distances. These concepts, which originated as attempts to solve metallurgical problems, have had experimental application for the case of aqueous solutions, often by the metallurgists themselves, who have sought to make use of the transparent properties of water and ice to aid in the investigation of general problems of phase change [e.g., Harrison and Tiller, 1963]. Weeks and Lofgren [1967] have applied these techniques to the specific case of the freezing of sodium chloride solutions with consideration of the case of sea ice; a good agreement with experiment has been shown.

Once the ice itself has been formed, further desalination occurs. The salt is removed from the bulk of the ice sheet by a number of possible drainage mechanisms, which have been discussed by Untersteiner [1967]. 


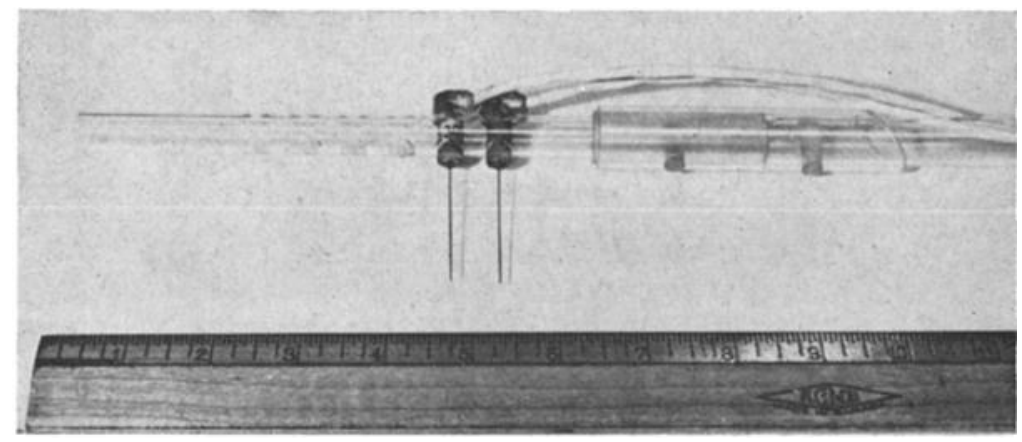

Fig. 1. Thermistor needle chain partially assembled during manufacture. The thermistor is within the needle tip. Scale in inches $\left(1^{\prime \prime}=2.54 \mathrm{~cm}\right)$.

\section{Data Collection}

The observations to be described were made at Cambridge Bay, Northwest Territories $\left(69^{\circ} 04^{\prime} \mathrm{N}, 105^{\circ} 00 \mathrm{~W}\right)$, during February and March 1968. The present studies were made in conjunction with other studies of the vertical convective circulation occurring under the ice sheet. The investigation area was specifically chosen in an attempt to reduce advection currents to a minimum. The bay has an approximate area of $8 \mathrm{~km}^{2}$ and a maximum depth of 85 meters and is connected to the open sea by a passage $14 \mathrm{~km}$ long and $1.2 \mathrm{~km}$ wide, which contains three sills 15 meters or less deep. The river flowing into Cambridge Bay is frozen solid after the end of September. The ice has no apparent horizontal movement and the tides are slight (0.65-meter maximum, 0.45-meter average). A tide crack surrounds the bay but is usually less than 20 meters from the shore. At the time of the experiment, the ice thickness was approximately 1.55 meters at a site 550 meters from the nearest land, in water 74 meters deep. The ice grew at a rate of approximately $7 \mathrm{~mm} /$ day from water of $28.7 \%$ salinity.

To make a full study of conditions at the ice-water interface, values of temperature and salinity should have been simultaneously re- corded in situ. From previous work (J. A. Elliott, unpublished manuscript, 1966) it was known that significant salinity variations could occur over distances of the order of a few millimeters, and no instrument available would enable such measurements to be made. Of necessity, therefore, temperature only was recorded. Lewis [1967] had shown that resolution was required to a few thousandths of a degree if detail of any possible movement of water was to be recorded. Experience with a variety of sensors and measurement systems operating in these extreme environmental conditions limited this accuracy to absolute values of $\pm 0.003^{\circ} \mathrm{C}$ on the international practical temperature scale of 1968 , though relative values could be discriminated to $\pm 0.001^{\circ} \mathrm{C}$ over a period of at least 2 weeks and to $\pm 0.002^{\circ} \mathrm{C}$ over the whole period of the experiment.

It is necessary to describe the experimental technique in some detail in order that the significance of the results may be appreciated. Thermistors mounted inside hypodermic needles $3.8 \mathrm{~cm}$ long with outside diameter of $0.8 \mathrm{~mm}$ were held in a plexiglass mount with sensitive elements in line at a separation of $1.5 \mathrm{~cm}$. Three such chains of six, six, and four needles, respectively, were used. Figure 1 shows such a chain partially assembled during manufacture. These chains were placed at a minimum thickness, at maximum thickness, and in an intermediate location in the ice sheet so that in each case the sensors were vertically in line and 20 $\mathrm{cm}$ below the existing ice-water interface. On an average, 1 month elapsed between the probe insertion and the successive envelopment of individual thermistor pin sensors by the growing ice sheet. Before data were recorded, photographs of the chains were taken in situ by an underwater camera, which showed very clearly that there was no observable perturbation in the shape of the ice-water interface due to the insertion of the needles.

In addition, a thermistor probe was attached to the end of a 3.5-meter length of $6-\mathrm{mm}$ stain- 
less steel tube, which was moved with its axis horizontal just under the growing ice sheet by dc stepping motors locked in synchronism with the $x$ axis of an $X Y$ plotter. Horizontal variations of temperature were thus recorded graphically. Structures of dimensions as small as $0.5 \mathrm{~mm}$ were thought to exist, and allowable traverse rates were restricted by the time constants of the thermistor pins which were better than 0.1 second.

The data logging system attached to the thermistor chains made measurements of relative accuracy to better than \pm 2 parts in $10^{5}$. The logging was continuously calibrated by the placement of a standard resistor in every fifth channel. Used in this mode, the logger required only short-term stability in order to achieve temperature recording of the accuracy mentioned. The usual sample rate was one channel every 0.5 second, which could be increased to one every 0.2 second if required.

A detailed study of the crystallographic structure of the ice sheet was made. It was thought that previous studies of this type had often been limited in value by the small size of the sample obtained. For example, conventional salinity studies have been made with a 7.5 -cm SIPRE corer, and most investigations appear to have been performed on blocks of ice having a horizontal section of not more than $1000 \mathrm{~cm}^{2}$. It was considered that ice samples of this size might contain only a portion of the significant features that would be observed in larger specimens and that serious errors could be introduced by assuming that what was observed in such samples could be applied to the ice sheet as a whole. For this reason considerable effort was expended in obtaining a sample of dimensions $2.2 \times 1.8 \times 1.6$ meters thick, weighing approximately $5900 \mathrm{~kg}$ with a bottom surface area of approximately $4 \mathrm{~m}^{2}$. This sample area was cut out with a chain saw, was raised with heavy construction equipment and was laid on its side on the ice sheet. Defining the direction of ice growth as along the negative $z$ axis with the origin at the ice-water interface, saw cuts were made in the planes $z=6, z=12$, and $z=18 \mathrm{~cm}$ across the whole section of the ice block. Subsequent slabs of ice were cut from the ice block in $z=$ constant planes but covering $1-\mathrm{m}^{2}$ cross section. These slabs were further dissected, photographed, and cut into thin sec- tions, which allowed an over-all picture of drainage features to be built up. Salinity profiles from several adjacent columns of ice with axes along the direction of growth were obtained by melting samples $16 \mathrm{~cm}$ in length and using a bench type induction salinometer.

\section{Brine Removal at Interface}

Figure 2 is a photograph of a vertical section through the ice-water interface. The main feature is a single large channel extending from top to bottom of the photograph. In addition, a multiplicity of small vertical tubes appear within a few centimeters of the interface. Detailed examination of $1 \mathrm{~m}^{2}$ of ice at the $z=1$ cm level showed that these small tubes had an average distribution density of 42 tubes $/ \mathrm{cm}^{2}$ with diameters in the range $0.3-0.5 \mathrm{~mm}$. The situation at the interface could not be determined accurately because of the freezing of superficial water when the ice block was removed from the ocean. The gradual transition from interplatelet grooves at the interface to cylindrical tubes has been described by Anderson and Weeks [1958]. It is thought that the tubes are equivalent to the solute transpiration pores described by Harrison [1965a]. Assur [1958] also describes these tubes and mentions a trail of inclusions of brine extending from the end of the tube up into the ice sheet. He also stated that the normal location of these tubes was between the platelet substructure of each columnar crystal. Our observations agree with his.

Although predominantly orientated along the $z$ axis, individual tubes could be found at various angles and sometimes were curved instead of straight. Occasionally, tubes were interconnected. Within a few centimeters of the interface there is a matrix of ice and tubes and grooves containing brine, the proportion of brine increasing toward the ice-water interface. The small tubes as described occupy approximately $5 \%$ of the interface surface area. Figure 3 illustrates schematically the distribution of the tubes and their size in relation to the thermistor probes used for temperature measurement.

Figures 4 and 5 are plots of the temperature recorded by thermistor pin chains as individual thermistors were successively enveloped by the growing ice sheet. Individual temperature read- 


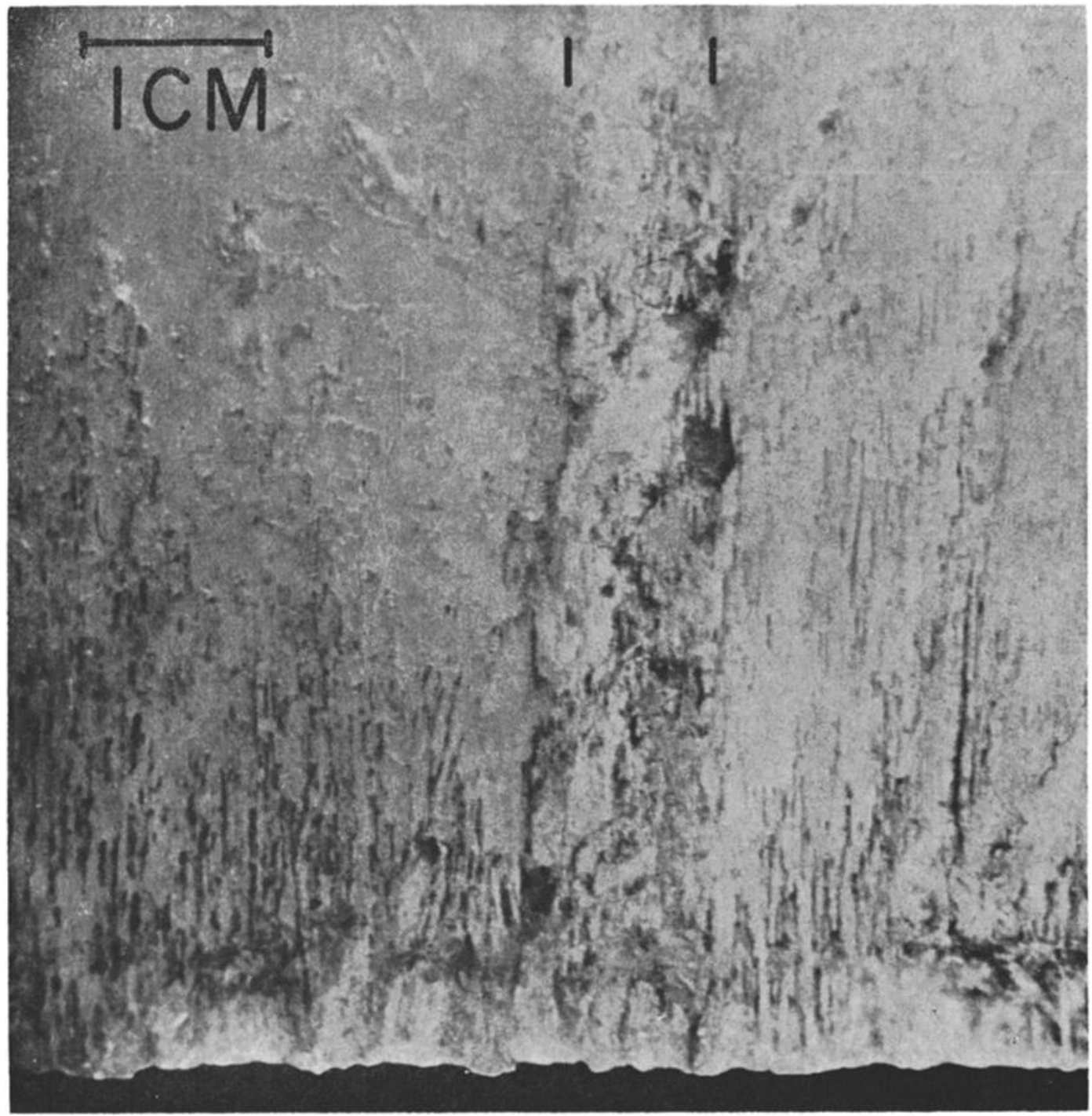

Fig. 2. Vertical sea ice section. The ice-water interface is near the bottom of the photograph. Two marks show the horizontal limits of a large vertical drainage channel which extends downward to the interface.

ings were taken at 20 - minute intervals, but supplementary high-speed records have shown that the figures contain all information toward the high-frequency end of the temperature fluctuation spectrum. It is noted that significant temperature fluctuations superimposed on the main temperature trend occur as the thermistor passes through the interface from sea water at a freezing point of $-1.579 \pm 0.003^{\circ} \mathrm{C}$. A rough periodicity appears, and major temperature minima occur on the line drawn on the figure. For an increase in temperature to occur at a given thermistor probe, it is clear that the meteorologically determined temperature gradient within the ice sheet must be changed or heat must be transported by fluid movement. Previous studies [Lewis, 1967] indicate that over the periodic time associated with the present fluctuations, no significant temperature change could be propagated from the surface of the ice down to the interface for ice of this thickness. Thus, an increase in temperature at the 


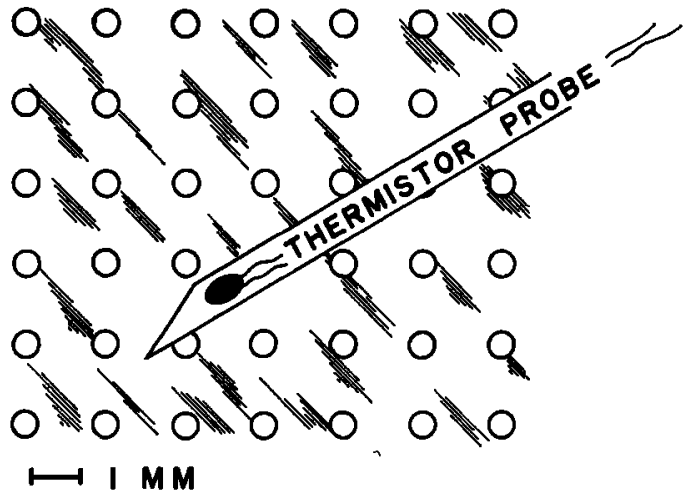

Fig. 3. Schematic showing the average convective tube distribution and diameter in relation to the thermistor probe.

thermistor probe requires an actual movement of sea water, i.e. convection. Yih [1959] has considered the problem of the onset of convection due to density gradients in infinite insulated vertical tubes and slots caused by vertical temperature gradients. The formal development of the analysis is the same whether the motion is caused by temperature or solute gradients, and the critical condition for the onset of convection is given by

$$
\partial \rho / \partial z=\mathcal{R} D(\rho) \mu(\rho) / g a^{4}
$$

where $\rho(z)$ is the fluid density, which is variable along the vertical $z$ axis, $D$ is the diffusivity of the physical quantity producing the density gradient, $\mu$ is the viscosity, $g$ is the acceleration due to gravity, $a$ is the tube radius or semi-width of the slot, and $R$, the critical Rayleigh number, has a value of 67.9 for the tube and 31.3 for the slot.

The actual tubes and slots are not of constant section, are of finite length, and do not have walls 'insulated' with respect to either heat or salt flow, for both occur in interstitial spaces as the brine is fractionally frozen because of the general growth of the ice sheet. Nevertheless, it is useful to attempt a qualitative interpretation of the convective process in terms of equation 1.

Under conditions of thermodynamic equilibrium the mean temperature gradient in the ice sheet defines a salinity gradient within a slot or tube and so a density gradient. From (1) this gradient will cause convection in all tubes of radii greater than a certain value. If $D=$ $7 \times 10^{-8} \mathrm{~cm}^{2} / \mathrm{sec}$ and $\mu=0.019 \mathrm{~g} / \mathrm{cm}$ sec and if, from Figure 4 , the temperature gradient in the ice sheet is taken as $0.07^{\circ} \mathrm{C} / \mathrm{cm}$ (giving $\left.d \rho / d z=0.001 \mathrm{~g} / \mathrm{cm}^{4}\right)$, convection would just occur in tubes of diameter $1.1 \mathrm{~mm}$ and slots of

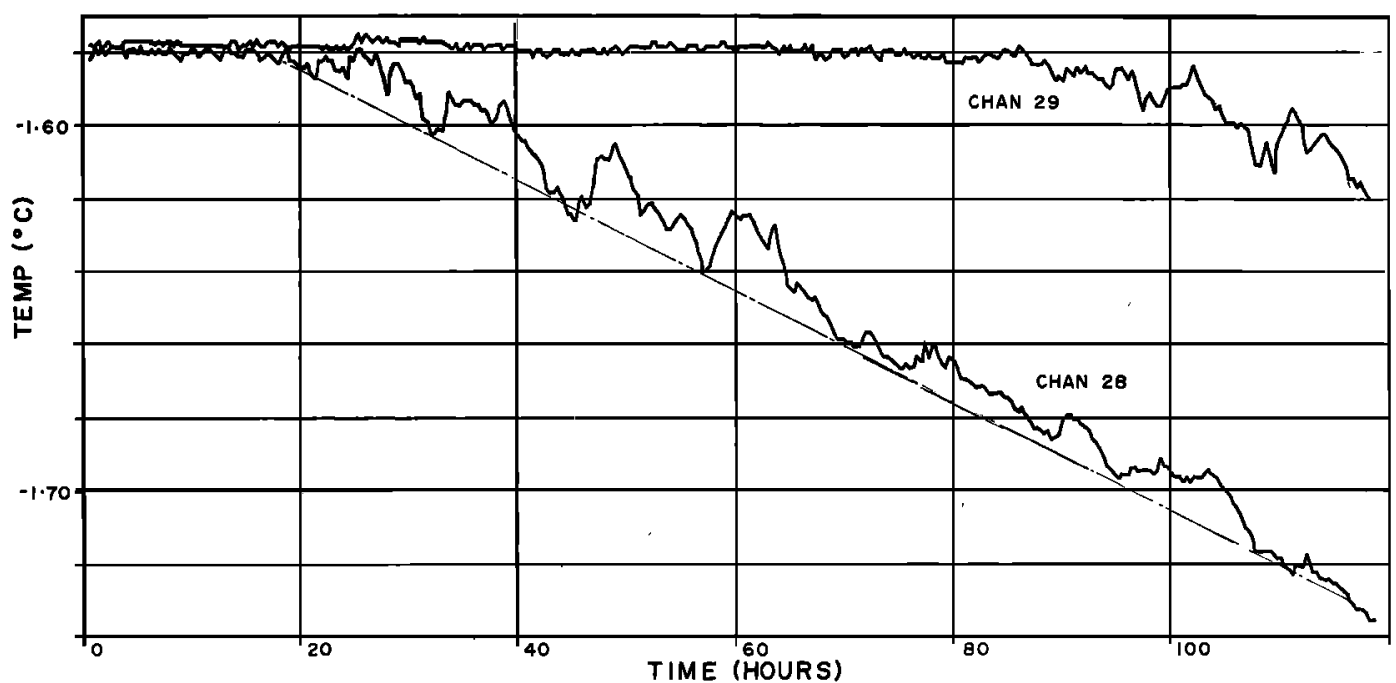

Fig. 4. Temperature recorded by thermistor pin chains as individual thermistors were successively, enveloped by the growing ice sheet. The diagonal line joining temperature minima corresponds to the mean temperature gradient produced by the meteorological conditions. The broken vertical lines with alphabetical labels mark specific events; see text for discussion. 


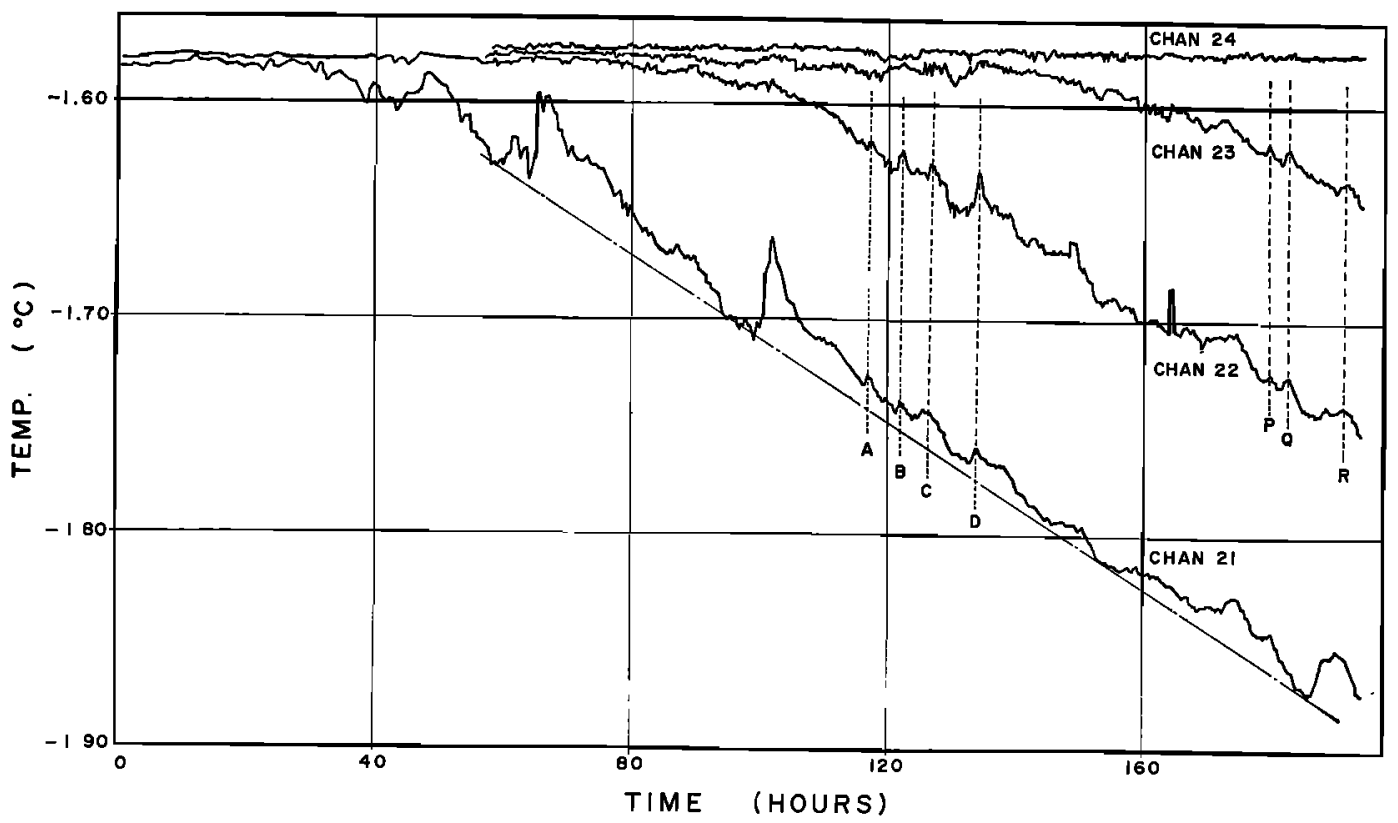

Fig. 5. See legend for Figure 4.

width $0.9 \mathrm{~mm}$. These values are about twice the values observed at the interface, which, according to the present analysis, would thus make the actual tubes well below 'cutoff' for convective fluid motion. As the fourth power of the tube radius is involved, it is anticipated that a density gradient at least an order of magnitude greater than that attributable to the mean meteorologically determined temperature gradient in the ice sheet must exist for convection to occur.

A typical tube is 2 or $3 \mathrm{~cm}$ long and, except for a few millimeters in the immediate vicinity of the interface, where the slot or groove topography predominates, is observed to be a right circular cylinder closed at the upper end by a slightly bulbous cap. As the ice sheet grows, it is considered that ice is deposited within the tube both on the cylindrical walls and in the end cap. This growth is limited, in the absence of axial brine movement, by the rapid increase in salinity as salt is rejected back into the interstitial brine. Thus growth of ice within the cap is retarded with respect to the general interface, and the tube elongates. The mean isotherms in the ice are considered to be parallel to the ice-water interface, so that, since the freezing point is very nearly a linear function of salinity over a small range, ice growth onto the cylindrical walls of a tube will leave $\partial \rho / \partial z$ within the tube unchanged for thermodynamic equilibrium. This is not true within the end cap of the tube, where any downward growth must increase both the density and the density gradient in the immediately adjacent brine. When this density gradient in the cap is about one order of magnitude greater than that existing within the main cylindrical portion of the tube, convection occurs. The cold dense brine within the tube is exchanged for less saline warmer water from beneath, which causes a local deformation in the isotherms and provides material for further ice growth. No theoretical description of this type of phenomenon exists to the best of our knowledge. An analysis of convection in a tube closed at one end [Lighthill, 1953] predicts that for given boundary conditions (different and simpler than those of present concern) a stagnant region will exist at the closed end of a tube of sufficient length. Lighthill's work has seen good experimental verification by Martin and Cohen [1954], so that it is reasonable to postulate that a stagnant region could exist at the upper end of the tube in the ice. Observation shows rapid radial ice growth or 'necking' a few millimeters below the bulbous 
end cap, which is thought to be a stagnant region. Eventually the end is sealed off and becomes a brine inclusion. This growth provides a source of salt to sustain convection and on seal-off the tube is shortened back to its original length. The isotherms must now return to their original state, parallel to the interface, as the excess heat is removed by conduction, and general ice growth proceeds until a density gradient sufficient to cause convection is once again produced at the upper end of the tube. The larger the tube diameter is, the less will be the gradient required to cause convection and the more frequent will be the convective process. Thus a larger tube will be provided with more material for growth in a given time than will a smaller tube. The diameter of all tubes at the interface should then approach a limiting value. This conclusion is supported by our observations, which show an average tube diameter of $0.4 \mathrm{~mm}$ with a standard deviation of $0.13 \mathrm{~mm}$ at $1 \mathrm{~cm}$ from the interface.

The records of Figures 4 and 5 may now be interpreted in terms of the above hypothesis. The lines joining the temperature minima on individual records show the lowest possible temperature that the given probe can have at that time and correspond to the meteorologically determined temperature gradient. Departures from this line are occasioned by local and temporary deformations of the isotherms caused by convective motion of brine within the ice-water matrix. Convection within a given tube will occur at a frequency determined by the over-all growth rate of the ice sheet as this would control the time taken to produce the critical density gradient required to initiate fluid motion.

It will be noted that certain features of Figure 5 labeled A, B, C, D show correspondence between temperature fluctuations recorded on channels 21 and 22, which were adjacent, and that other features, labeled $P, Q$, and $R$, also appear to correspond between channels 22 and 23 . However, many other significant features do not appear to have a similar correspondence. By contrast, Figure 4 does not show any correspondence between temperature fluctuations registered at the upper and lower probes when both were in the ice matrix. Records obtained from the three chains separated horizontally by about 5 meters, each chain having probes in the ice at the same time, show that convective overturns did not occur simultaneously at the three locations. It is thought that convection occurs individually, tube by tube. The departure of the records of Figures 4 and 5 from the meteorological temperature equilibrium line is interpreted as being the result of superimposed temperature signals of the same order of frequency but with random initial phase, the amplitudes of the component temperature fluctuations being controlled by the distance of the probe from the individual tube. As the ice sheet grows, the probe is removed from the region of convection and the timetemperature curves consequently approach more closely the meteorological temperature equilibrium line set up by the prevailing atmospheric conditions. This has been shown experimentally by Lewis [1967] when much longer but less accurate records of temperature were obtained as a thermistor was enveloped by a growing ice sheet. In no case recorded in the present experiment did the temperature fluctuation within the ice produce a corresponding fluctuation at the location of the next-in-line thermistor in the water beneath. Thus the effects associated with convection in the small tubes are not thought to be evident a significant distance into the underlying water.

\section{Brine Removal from Ice Interior}

Figure 2 shows a section of a large tube parallel to the $z$ axis and approximately $7 \mathrm{~mm}$ in diameter which was seen on examination to penetrate far up into the interior of the ice sheet. It conforms to the general structural pattern described by Bennington [1967] as 'A first generation drainage channel.' The average distribution was one large channel every 180 $\mathrm{cm}^{2}$ over the area of $1 \mathrm{~m}^{2}$ studied in detail, giving a mean distance of $13.4 \mathrm{~cm}$ between channel centers. A similar distribution was noted over the entire cross section. In $z=$ constant sections the large channels show a starburst pattern surrounding a central drainage area of very variable size, the arms of the star often following crystal boundaries. The average diameter for the over-all pattern is $4 \mathrm{~cm}$, which decreases with distance from the interface to vanishing point at about $z=90 \mathrm{~cm}$. The individual radial arms typically were 2 to $3 \mathrm{~cm}$ long and 2 to $8 \mathrm{~mm}$ wide. Figure 6 shows a 


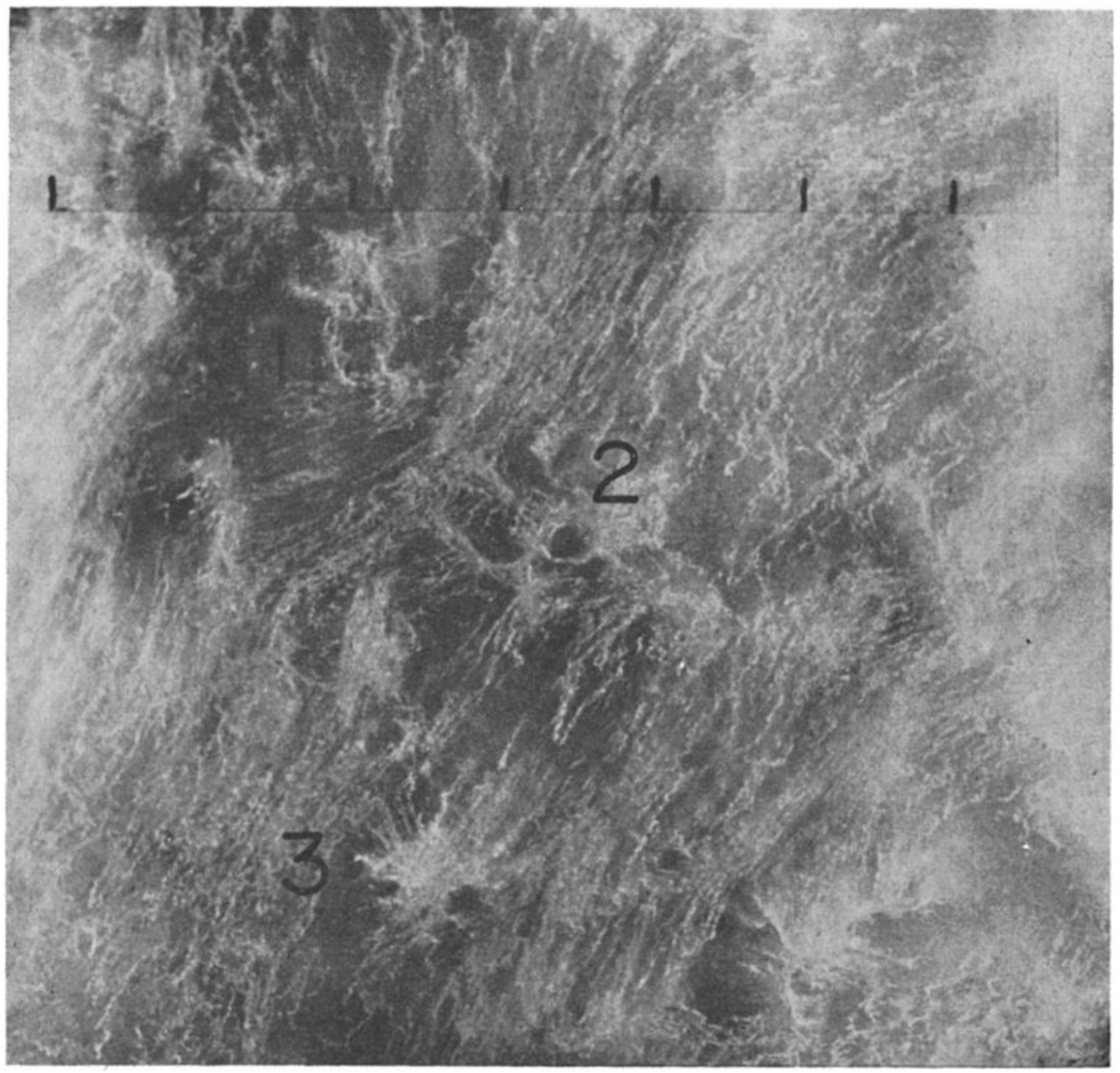

Fig. $6 a$. Horizontal sea ice section at level $z=9 \mathrm{~cm}$ with respect to the interface. Numbers on the photographs (here and following) refer to the same large drainage channel at each level. The scale shown at the top of the photographs has 10-cm intervals.

series of sections taken at various $z=$ constant planes where individual features may be traced. These drainage channels were found to be filled with a porous polycrystalline mass, which is illustrated in Figure 7. The argument already made for convection in the small tubes at a given temperature gradient would indicate that any large open tube must rapidly decrease in diameter, owing to the continual exchange of water. It is considered that in natural sea ice at least a skeleton of polycrystalline material is present sufficient to inhibit convective exchange of water with the sea beneath at the meteor- ologically determined temperature gradient. Trapped water will be frozen in situ after the specimen ice block is removed from the sheet.

In tracing a given drainage channel through the ice sheet, it should be noted that geometric similarities are only poorly preserved between $z=$ constant sections. In certain complex cases an element of personal judgment may enter into determining which of the arms correspond. Figure 8 is a schematic drawing of a brine drainage channel showing that the feed arms are comprised of inclusions forming conical patterns with apices on the main drainage channel and 
with semiangles between $40^{\circ}$ and $54^{\circ}$. These features appear to be characteristic of all drainage areas of this type, noted by Bennington [1967, p. 851]. The largest, most well developed inclusions exist in the first 10 to $20 \mathrm{~cm}$ from the interface. The higher, more diffuse structure is probably a fossil remnant of the previous active area. This would require that the structure is growing continuously in length as opposed to a structure of fixed length moving downward behind an advancing interface.

Although it appears certain that the features described do in fact drain brine from the ice interior, the process by which the brine migrates is unclear. Untersteiner [1967] has summarized the possible mechanisms; in the pres- ent context (growth season only) they are (a) solute diffusion, (b) gravity drainage, and (c) expulsion.

Solute diffusion depends on the well-known fact that a brine inclusion entrapped in ice having a temperature gradient between its ends migrates toward the warmer end of the ice block. A description of this phenomenon from Harrison [1965b] also notes that upon occasion the inclusions migrate along the $C$ axis of the ice crystal rather than along the temperature gradient, as is common. Taking values typical for the ice cover being considered gives a velocity of $3 \times 10^{-4} \mathrm{~cm} / \mathrm{hr}$ for brine inclusion movement. All authors agree that for gradients commonly met in normal sea ice brine drainage

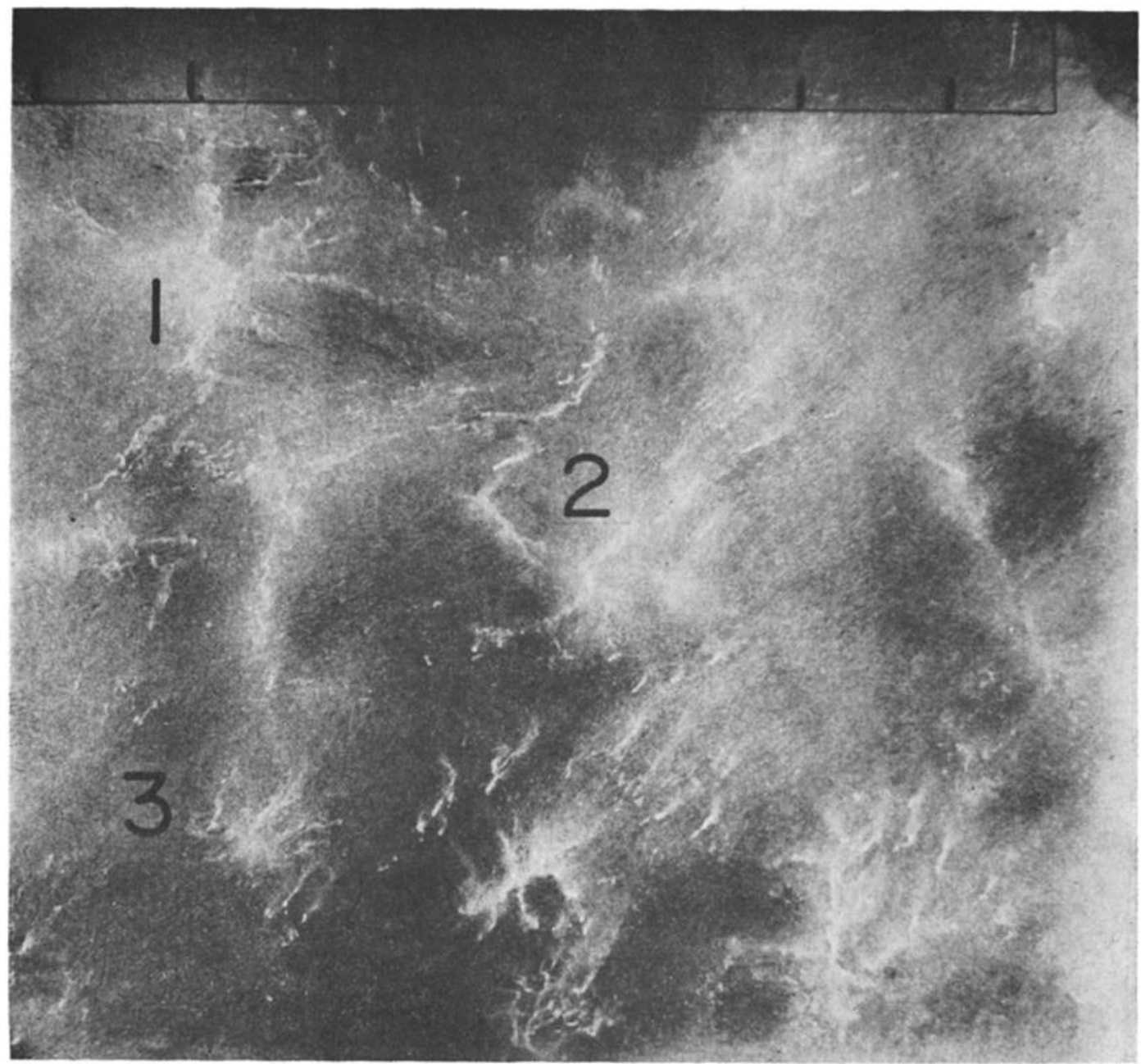

Fig. $6 b$. Level $z=28 \mathrm{~cm}$. 


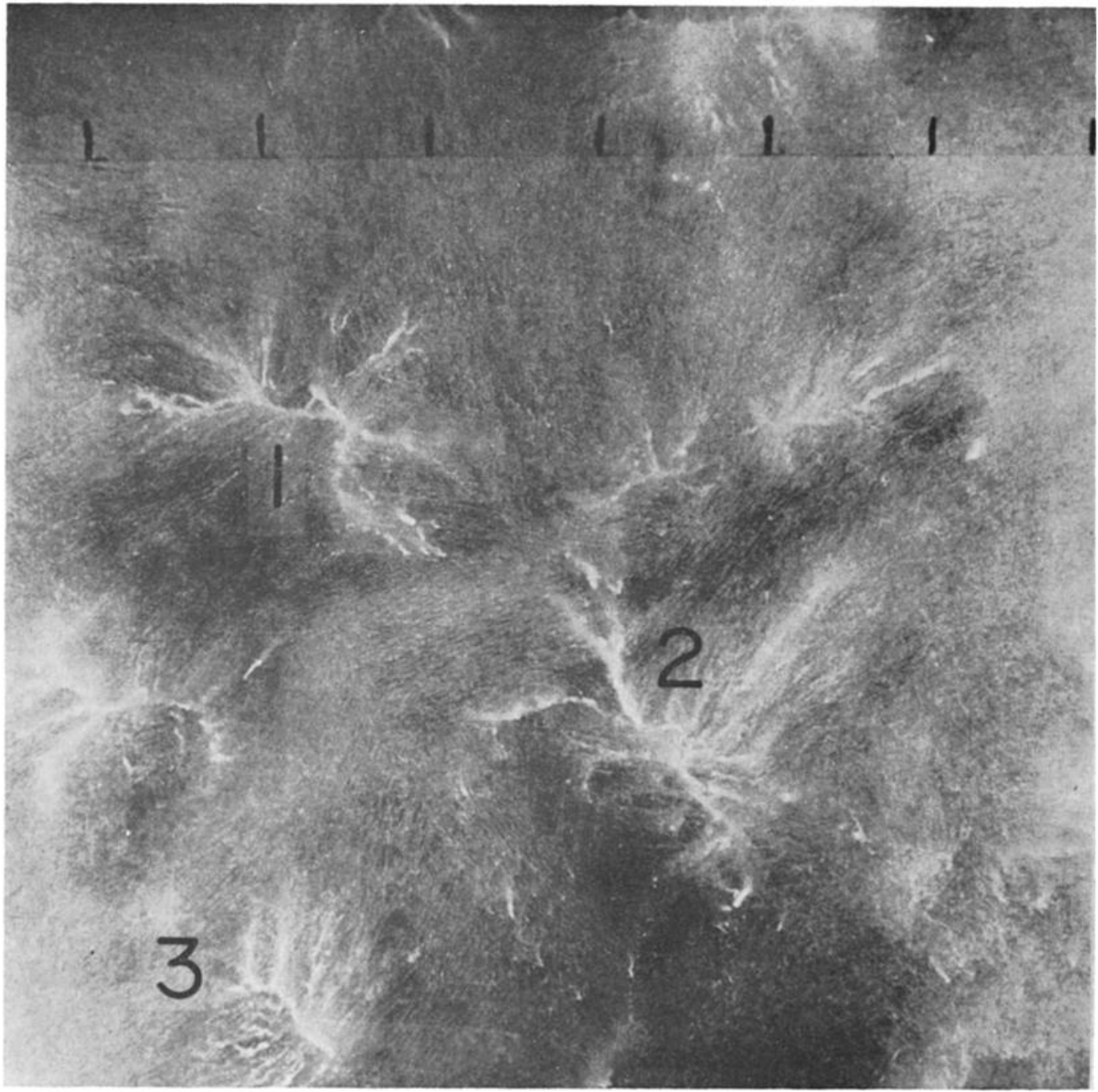

Fig. 6c. Level $z=46 \mathrm{~cm}$.

effected by this process alone is negligible. Gravity drainage implies movement of brine due to differences in density between brine in the interior of the ice and brine in sea water outside. This constitutes a convective system similar to that described for the small tubes, provided that there is hydrostatic communication from the interior of the ice to the sea water beneath. It is thought [Bennington, 1967] that this communication may be provided by the third mechanism expulsion, which is migration of brine due to cracking produced by differential thermal expansion, or, in our case, due to frac- tional freezing of the brine inclusions and the buildup of high internal pressures due to the increased volume taken up by the newly formed ice. Clearly, such cracks would tend to follow lines of natural weakness, such as crystal boundaries. Once released from its initial captivity within a particular inclusion the brine in the upper levels of the sea ice would tend to etch its way through the lower levels, because of its high salinity, until dilution by the etched ice brought it into thermodynamic equilibrium at a particular temperature level. The question also arises of the origin of the primary drainage 
channel, which, as it forms a natural weakness within the ice sheet, would be the focus toward which any cracks would naturally tend to propagate. Once again, in agreement with Bennington, we consider that these primary channels may trace the locus of the point at which brine streamers leave the ice water interface transporting salt downward into the ocean. An observation in the laboratory is that a multitude of tiny ice spicules surround descending salt-rich streamers because of the heat sink the streamers provide for the immediately adjacent sea water. These naturally will float upward and may be the origin of the polycrystalline ice masses found within primary drainage channels. The structures described and the interpretation given postulate a horizontal salt flux within the ice mass. The aforementioned diagonal striations and tubes that mark the arms of the drainage pattern form strong circumstantial evidence for this assertion, and the work of many authors, among them Weeks and Lee [1962], has shown very large variations in salinity of adjacent ice cores. Table 1 shows the variation in salinity of adjacent rectangular blocks of ice $5 \times 5 \times 16 \mathrm{~cm}$ taken from the

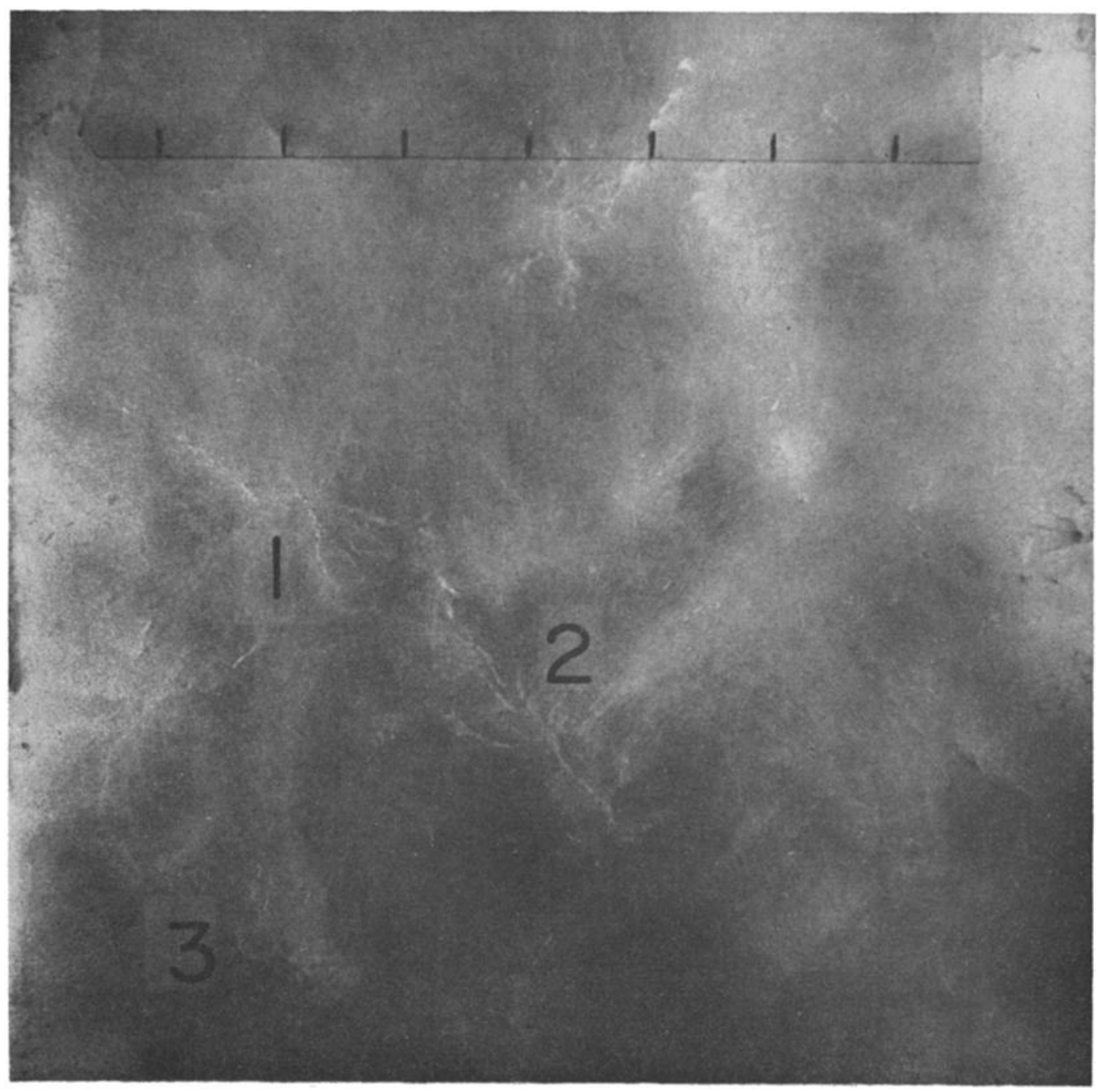

Fig. 6d. Level $z=56 \mathrm{~cm}$. 

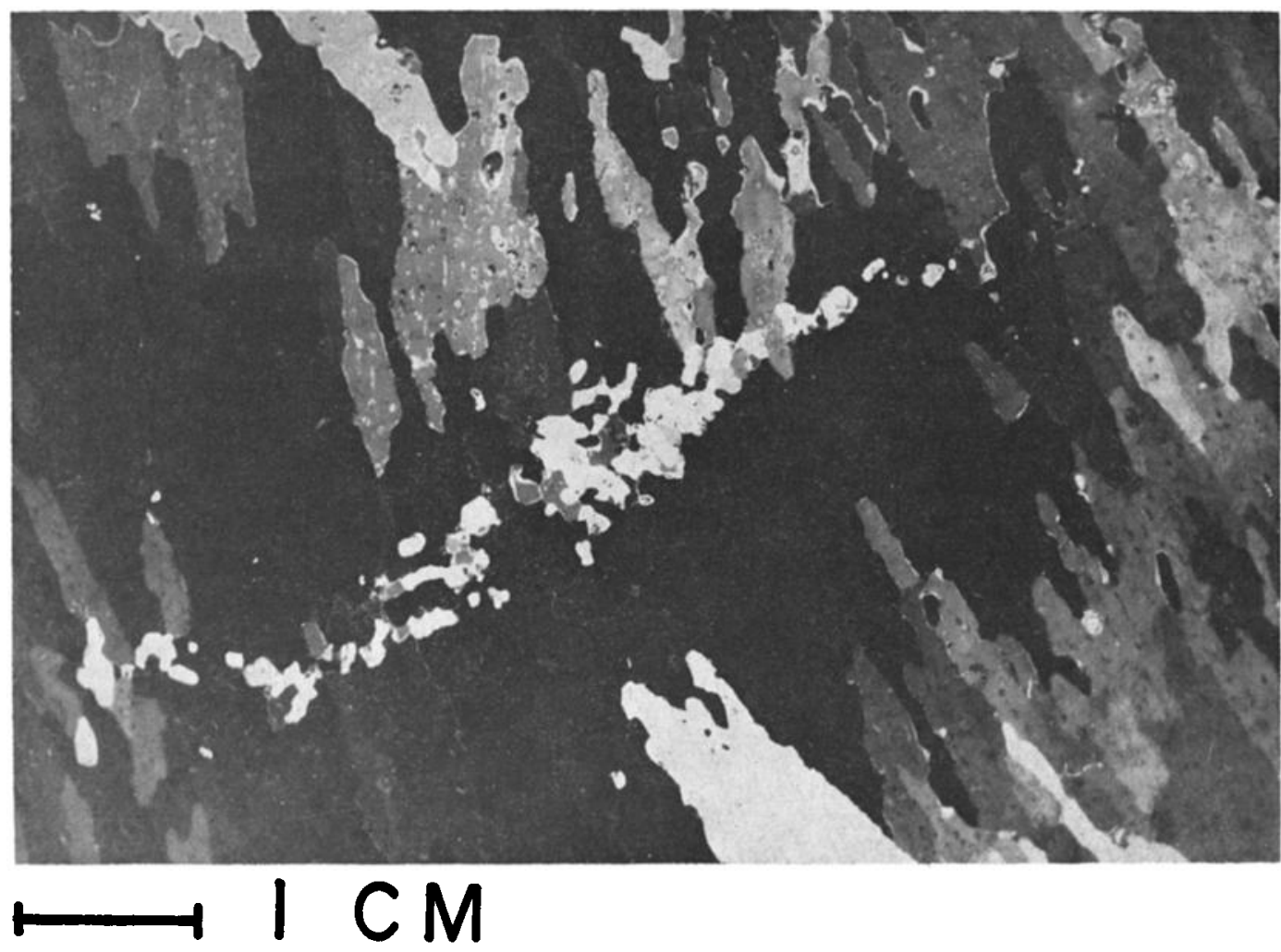

Fig. 7. A drainage channel arm filled with a polycrystalline mass viewed through crossed polaroids.

sample from which the present observations of drainage structures were made.

Clearly the rejection of salt at the interface implies a continual convective motion of brinerich streamers and a balance of upward-moving waters from below. An attempt has been made to discover what, if any, horizontal variation in temperature exists in the sea water immediately below the growing ice sheet. By using the aforementioned traversing probe over very long periods of operation a few isolated events were discovered that showed the presence of blobs of relatively warm water. Figure 9 shows one of these records off the point plotter and for comparison the record obtained in traversing under a $15-\mathrm{cm}$ hole drilled through the ice sheet is given. It is noted that there is a 4-cm-wide downward-moving streamer of cold water under this hole; the record taken under the undisturbed ice sheet shows only small warm water masses. Further information was obtained from one of the thermistor chains, the record of which is shown in Figure 10. It is seen that as time increases a thin layer of warm water

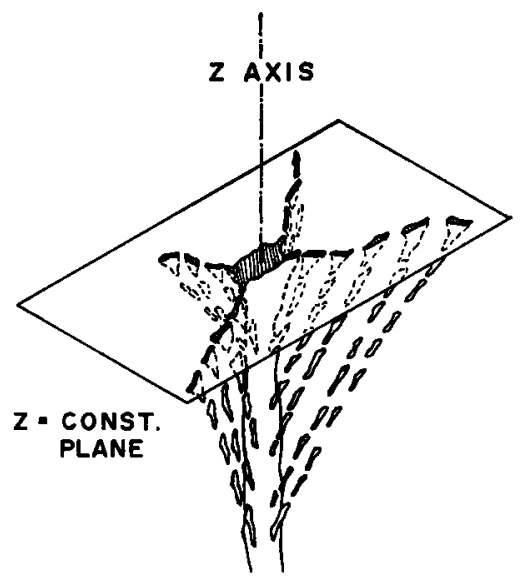

Fig. 8. Schematic drawing of a brine drainage channel and its feed arms. Feed arms are formed of inclusions inclined to the vertical at angles in the range $40^{\circ}-54^{\circ}$. 
TABLE 1. Mean Salinity $\left(\mathscr{O}_{0}\right)$ and Standard Deviation, $\sigma$, between Indicated Levels

\begin{tabular}{lcccccccccc}
\hline & \multicolumn{1}{c}{$Z$, Distance, cm } \\
\cline { 2 - 10 } & $11-27$ & $27-43$ & $43-59$ & $59-75$ & $75-91$ & $91-107$ & $107-123$ & $123-139$ & $139-155$ \\
\hline Number of samples & 5 & 10 & 10 & 9 & 10 & 10 & 10 & 10 & 10 \\
Salinity, \%o & 3.48 & 4.09 & 4.15 & 4.76 & 4.11 & 1.48 & 1.26 & 0.52 & 2.57 \\
Standard deviation, $\sigma$ & 0.41 & $\mathbf{0 . 5 2}$ & 0.43 & 0.36 & 0.34 & 0.25 & 0.18 & 0.26 & 0.85 \\
\hline
\end{tabular}

Note

$Z$ origin is at the water-ice interface with distance increasing upward.

caused an increase in temperature as registered by one thermistor probe only. The layer stayed in the vicinity for a period of 4 hours.

\section{Conclusion}

Brine is rejected from the growing ice-water interface both by diffusive means and by a cyclic convective system operating in the small tubes situated between ice platelets. The birth of each brine inclusion is registered by a tem- perature fluctuation in its immediate vicinity. There is very little, if any, vertical motion of brine-rich water immediately below the ice except at select locations indicated by primary drainage channels. The dense water moves toward these locations in thin layers immediately beneath the ice and in compensation thin layers of warm water move into the region, the overall pattern being one of penetrative convective cells. Records taken of temperature fluctuations

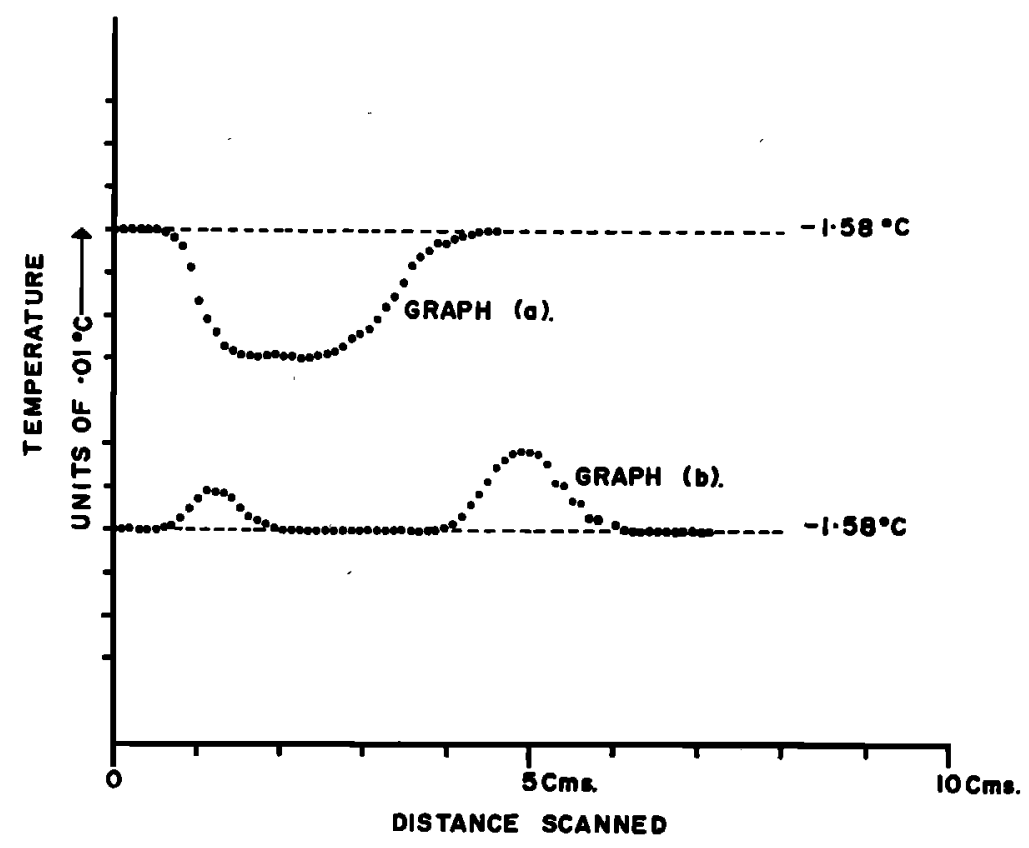

Fig. 9. Horizontal temperature variations beneath the sea ice as recorded by a traverging thermistor needle. Graph $a$ shows the temperature record upon traversing beneath a 15-cmdiameter hole drilled through the sea ice. Graph $b$ records one of the very infrequent natural temperature perturbations seen beneath the ice sheet.' Traverse speeds $(a) 0.826 \mathrm{~cm} / \mathrm{sec},(b)$ $0.269 \mathrm{~cm} / \mathrm{sec}$. 

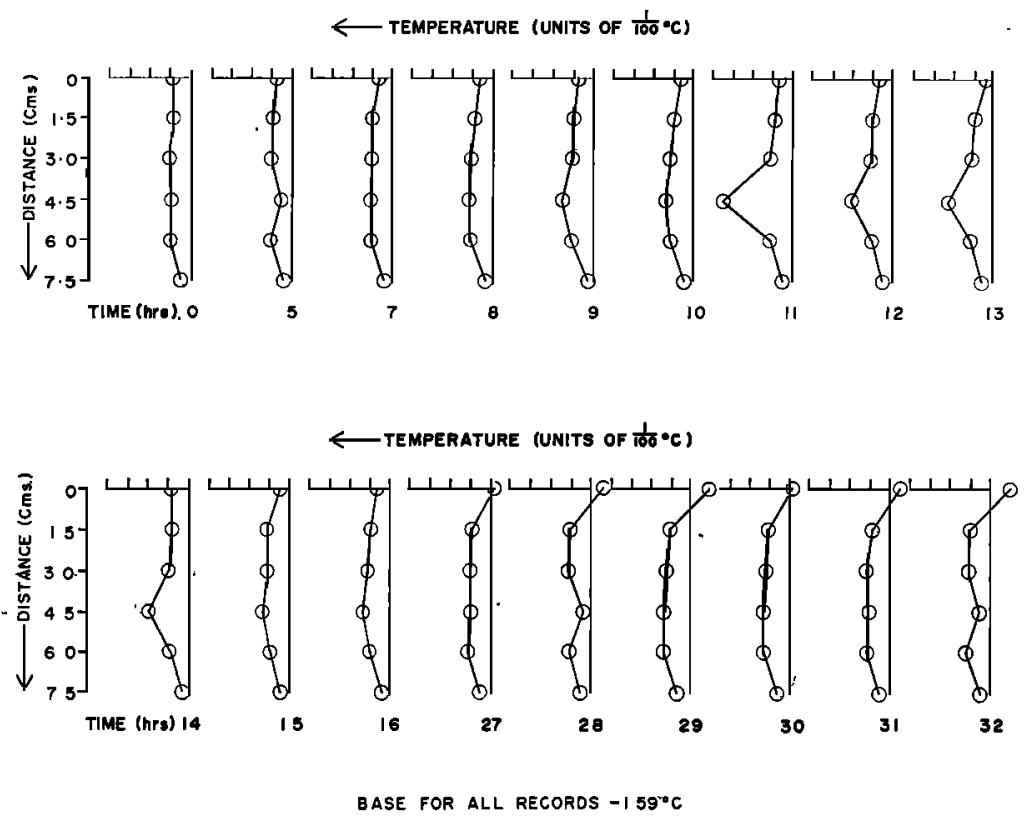

Fig. 10. Vertical temperature profiles immediately beneath the sea ice as recorded by a chain of thermistor needles at times close to their envelopment. (Accuracy of temperature measurement is $\pm 0.003^{\circ} \mathrm{C}$, which is the radius of the circle used to plot each reading.) The distance scale gives the thermistor separation relative to the uppermost thermistor, which, from the time 27 hours onward, shows marked cooling as it is enclosed by the growing ice sheet.

at various levels in the underlying sea and their interpretation are described by the authors' colleague (E. R. Walker, in preparation, 1969).

\section{REFERENCES}

Anderson, D. L., and W. F. Weeks, A theoretical analysis of sea ice strength, Trans. Amer. Geophy. Union, 39(4), 632-640, 1958.

Assur, A., Composition of sea ice and its tensile strength, in Arctic Sea Ice, Nat. Acad. Sci., Nat. Res. Council, Publ. 698, p. 106, Washington, D. C., Dec. 1958.

Bennington, K. O., Desalination features in natural sea ice, J. Glaciol., 6(48), 845-857, 1967.

Burton, J. A., R. C. Prim, and W. P. Slichter, The distribution of solute in crystals grown from the melt, 1, Theoretical, J. Chem. Phys., 21(11), 1987-1991, 1953.

Burton, J. A., and W. P. Slichter, The distribution of solute elements: Steady-state growth, in Transistor Technology, vol. 1, edited by H. E. Bridger, p. 71, Von Nostrand, New York, 1958.

Cole, G. S., and W. C. Winegard, Thermal convection during horizontal solidification of pure metals and alloys, J. Inst. Metals, 93, 153-164, 1964.

Harrison, J. D., Solute transpiration pores in ice, .. J. Appl. Phys. \$6(1), 326-327, 1965a.
Harrison, J. D., Measurement of brine droplet migration in ice, J. Appl. Phys., 36(12), 3811$3815,1965 b$.

Harrison, J. D., and W. A. Tiller, Controlled freezing of water, in Ice and Snow, edited by W. D. Kingery, p. 215, M.I.T. Press, Cambridge, Mass., 1963.

Lewis, E. L., Heat flow through winter ice, in Physics of Ice and Snow, International Conference on Low Temperature Science, Proceedings, vol. 1, part 1, edited by H. Oura, p. 611, Hokkaido University, Sapporo, Japan, 1967.

Lighthill, M. J., Theoretical consideration on free convection in tubes, Quart. J. Mech. Appl. Math., 6, 398-439, 1953.

Martin, B. W., and H. Cohen, Heat transfer by free convection in an open thermosyphon tube, Brit. J. Appl. Phys., 6, 91, 1954.

Tiller, W. A., K. A. Jackon, J. W. Rutler, and B. Chalmers, The redistribution of solute atoms during the solidification of metals, Acta Met., 1, 428-437, July 1953.

Untersteiner, N., Natural desalination and equilibrium salinity profiles of old sea ice, in Physics of Snow and Ice, International Conference on Low Temperature Science, Proceedings, vol. 1, part 1, edited by H. Oura, p. 569, Hokkaido University, Sapporo, Japan, 1967. 
Wagner, C., Theoretical analysis of diffusion of solutes during the solidification of alloys, $J$. Metals, 200, 154-160, Feb. 1954.

Weeks, W. F., and D. S. Lee, The salinity distribution in young sea ice, Arctic, 12(2), 92$108,1962$.

Weeks, W. F., and G. Lofgren, The effective solute distribution coefficient during the freezing of $\mathrm{NaCl}$ solutions, in Physics of Snow and Ice,
International Conference on Low Temperature Science, Proceedings, vol. 1, part 1, edited by H. Oura, p. 579, Hokkaido University, Sapporo, Japan, 1967.

Yih, C., Thermal instability of viscous fluids, Quart. J. Appl. Math., 17(1), 25-42, 1959.

(Received August 22, 1969; revised October 28, 1969.) 